\title{
Synthesis of Water-Soluble Star Polymers Based on Cyclodextrins
}

\author{
L. KOTRCHOVÁ ${ }^{1}$, T. ETRYCH ${ }^{1}$ \\ ${ }^{1}$ Institute of Macromolecular Chemistry of the Czech Academy of Sciences, Prague, Czech \\ Republic
}

Received May 24, 2018

Accepted June 28, 2018

\begin{abstract}
Summary
Novel star polymers based on the water-soluble $N$-(2-hydroxypropyl)methacrylamide (HPMA) copolymer and cyclodextrin were synthesized and the physico-chemical behavior of these precursors was studied. Semitelechelic HPMA copolymers were grafted onto the cyclodextrin core, thus forming star-like structure. Both prepared systems were designed as possible polymer carriers for the controlled release of cytostatic drugs, which after the drug release and degradation will be eliminated from the organism. Two synthesis approaches were used to obtain similar polymer carriers with different degradation rates. All the polymers were prepared by reversible additionfragmentation chain-transfer polymerization, which guarantees low dispersity of the prepared systems.
\end{abstract}

\section{Key words}

HPMA copolymers • RAFT polymerization • Star polymers • Drug delivery system

\section{Corresponding author}

T. Etrych, Department of Biomedicinal Polymers, Institute of Macromolecular Chemistry of the Czech Academy of Sciences, Heyrovského nám. 2, 16206 Prague 6, Czech Republic. E-mail: etrych@imc.cas.cz

\section{Introduction}

Thirty years ago, Maeda and colleagues described the enhanced permeability and retention effect (EPR) (Matsumura and Maeda 1986), which has become a generally accepted phenomenon for passive targeting of cytostatics to solid tumors. Since that time a considerable number of water-soluble polymer carriers with covalently attached cytostatics suitable for delivery to tumor tissues have been designed and described. Generally, cytostatics attached via biodegradable spacers, which are cleavable in tumor tissue, are inactive during blood circulation. A suitable biodegradable linker, e.g. pH-sensitive or enzymatically degradable, allows controlled drug activation in the target tumor tissue (Kopecek et al. 2001, Singer et al. 2001, Nan et al. 2004, Maeda 2012). The use of polymer carriers for the controlled delivery of lowmolecular-weight cytostatic drugs yields several advantages, including prolonged polymer drug circulation in the blood and higher accumulation of the carried drugs in tumor tissue, enabling highly effective tumor therapy with minimized side effects (Etrych et al. 2012, Kostka and Etrych 2016).

One of the most widely studied water-soluble synthetic polymer carriers are copolymers based on $\mathrm{N}$-(2hydroxypropyl)methacrylamide (HPMA) (Lidický et al. 2016, Pola et al. 2016, Ulbrich et al. 2016). HPMA copolymers are generally synthesized by radical polymerization. Recently, controlled reversible addition fragmentation chain transfer (RAFT) polymerization has been employed for the synthesis of highly defined HPMA copolymer precursors with very low dispersity below 1.2 and high functionality of the polymer end-groups (0.9-1.0). (Šubr et al. 2013, Chytil et al. 2015). The high end-group functionality of linear polymers facilitates the synthesis of low-dispersed high-molecular-weight polymer carriers with grafted or star-like structures.

Macromolecules accumulate to a higher extent in tumors than smaller molecules due to their longer circulation in the blood and EPR-based accumulation. Recently, various structures of water-soluble HPMA polymer carriers, e.g. diblocks, grafted, branched and star polymers conjugates, have been studied in detail (Etrych et al. 2010, Etrych et al. 2011a, Etrych et al. 2011b). The high-molecular-weight polymer carriers with higher 
hydrodynamic volume accumulate to a higher extent in tumor tissue than linear copolymers. Despite their enhanced accumulation in tumors, the safe elimination of these high-molecular-weight carriers from the body by renal filtration has not been fully solved yet. The renal threshold for polymer carriers based on HPMA is approximately $50-70,000 \mathrm{~g} \cdot \mathrm{mol}^{-1}$ (Etrych et al. 2012) and also depends on the structure of the pHPMA carrier, e.g. linear or star. Indeed, star-like polymer doxorubicin (dox) conjugates with a polyamidoamine (PAMAM) dendrimer core and HPMA copolymer arms accumulated in solid tumors in mice considerably more than the corresponding linear polymer conjugates with dox. Considering that the PAMAM dendrimer core is non-biodegradable, the starlike polymer precursors with a biodegradable enzymatically or reductively cleavable spacer between the core and the polymer arms was designed in order to guarantee safe elimination from the organism (Etrych et al. 2011).

In this study, we focus on the design and synthesis of new biodegradable high-molecular-weight star polymer conjugates based on HPMA copolymers grafted onto $\gamma$-cyclodextrins serving as the biodegradable core. Cyclodextrins (CDs) are cyclic oligosaccharides with a cone-shaped cavity formed by $\alpha-1,4$-linked D-glucopyranose units. The most widely used CDs are $\alpha$-, $\beta$-, and $\gamma$-CDs with 6, 7 and 8 glucose units (Zhang and Ma 2013). Chemically modified CDs are used widely in the pharmaceutical industry; they are known as host molecules for various guest hydrophobic substances and are being studied in the field of supramolecular chemistry for supramolecular polymer preparation (Harada et al. 2009, Zhang and Ma 2013).

\section{Methods}

\section{Materials}

Methacryloyl chloride, 4,4'-azobis(4-cyanopentanoic acid), 2,2'-azobis(isobutyro-nitrile) (AIBN), $N$-ethylmaleimide trifluoroacetate, 6-aminohexanoic acid, methyl 6-aminohexanoate hydrochloride, $N, N^{\prime}$-dicyclohexylcarbodiimide, tert-butylcarbazate, trifluoroacetic acid (TFA), 2,4,6-trinitrobenzene-1-sulfonic acid (TNBSA), 1-ethyl-3-(3-dimethylaminopropyl)carbodiimide (EDC), dimethylsulfoxide (DMSO), dimethylacetamide (DMA), tert-butanol, $N$-hydroxysuccinimide (NHS), succinic anhydride, $N, N$-dimethylpyridin-4-amine and $\gamma$-cyclodextrins were purchased from Sigma-Aldrich Inc. 10-(11,12-didehydrodibenzo[b,f]azocin-5(6H)-yl)- 10-oxodecanoic acid (dibenzocyclooctyne-acid (DBCOacid)) was purchased from Click Chemistry Tools. All other chemicals and solvents were of analytical grade. Solvents were dried and purified by conventional procedures and distilled before use.

\section{Synthesis of monomers}

$N$-(2-hydroxypropyl)methacrylamide (HPMA) and $N$-(tert-butoxycarbonyl)- $N$ '-(6-(methacryloylamino) hexanoyl)hydrazine (Ma-Ah-NHNH-Boc) were synthesized as described earlier (Ulbrich et al. 2000, Ulbrich et al. 2004).

\section{Synthesis of the initiator}

The initiator 2-[1-cyano-1-methyl-4-oxo-4-(2thioxo-thiazolidin-3-yl)-butylazo]-2-methyl-5-oxo-5-(2thioxothiazolidin-3-yl)-pentanenitrile (AIBC-TT) was prepared as described previously (Šubr et al. 2006). Elemental analysis: calculated/found: C 44.79/45.10\%; H $\quad 4.59 / 4.69 \%$; N 17.41/16.89\%; S 26.57/26.05\%. ESI-MS: $m / z=504.83(\mathrm{M}-\mathrm{Na})^{+}$.

The initiator $\quad \mathrm{N}$-(3-azidopropyl)-4-[3-(3-azidopropylcarbamoyl)-1-cyano-1-methylpropylazo]-4-cyano-4methylbutyramide (AIBC- $\mathrm{N}_{3}$ ) was prepared as described previously (Šubr et al. 2013). Elemental analysis: calculated/found: C 48.64/49.04\%, H $6.35 / 5.87 \%$, N 37.81/37.53 \%. ESI-MS: $m / z=466.67(\mathrm{M}-\mathrm{Na})^{+}$.

\section{Synthesis of the functionalized chain transfer agent}

The RAFT chain transfer agent 1-cyano-1methyl-4-oxo-4-(2-thioxothiazolidin-3-yl)butyl ester of dithiobenzoic acid (CTA-TT) was synthesized according to the literature (Huang et al. 2011). ESI-MS: $m / z=380.92$ $(\mathrm{M}-\mathrm{Na})^{+}$.

The RAFT chain transfer agent 3-(3-azidopropylcarbamoyl)-1-cyano-1-methylpropyl ester of dithiobenzoic acid $\left(\mathrm{CTA}-\mathrm{N}_{3}\right)$ was prepared as described previously (Šubr et al. 2006). ESI-MS: $m / z=384.08$ $(\mathrm{M}-\mathrm{Na})^{+}$.

\section{Modification of cyclodextrins}

$\gamma$-cyclodextrin with NHS groups was prepared by esterification of the hydroxyl groups of $\gamma$-cyclodextrin with succinicanhydride and subsequent activation with NHS. $\gamma$-cyclodextrin $(6 \mathrm{mg}$; $0.0046 \mathrm{mmol})$ was modified using succinicanhydride $(10.7 \mathrm{mg} ; 0.11 \mathrm{mmol})$ in $160 \mu \mathrm{l}$ anhydrous DMA in the presence of DMAP. After $24 \mathrm{~h}$ of stirring, NHS (10.7 mg; $0.093 \mathrm{mmol})$ and EDC (12.3 mg; $0.08 \mathrm{mmol}$ ) were added to the reaction and the mixture 
was stirred at $0{ }^{\circ} \mathrm{C}$ for the next $18 \mathrm{~h}$. The product was separated by precipitation to diethyl ether, filtered and dried under vacuum. The product was characterized by MALDI-TOF.

$\gamma$-cyclodextrin with DBCO groups was prepared by esterification of $\gamma$-cyclodextrin with DBCO-acid. DBCO-acid (18 mg; $0.046 \mathrm{mmol}), \quad$ EDC (17.6 mg; $0.092 \mathrm{mmol}$ ) and a catalytic amount of DMAP were dissolved in $250 \mu \mathrm{l}$ DMA and stirred for $2 \mathrm{~h}$ at $5{ }^{\circ} \mathrm{C}$. Afterwards, $\gamma$-cyclodextrin $(6 \mathrm{mg} ; 0.0046 \mathrm{mmol})$ in $60 \mu \mathrm{l}$ DMA was added to the solution of DBCO-acid and the solution was stirred overnight. The product was separated by precipitation to ethyl acetate, filtered and dried under vacuum. The product was characterized by MALDI-TOF and its purity was verified by HPLC.

\section{Synthesis of linear polymer precursors}

The polymer precursors were prepared by controlled radical RAFT polymerization. The linear polymer precursor with the amino end group at the $\alpha$-end chain was prepared in two steps. Firstly, the polymer with the main-chain end located at the thiazolidine-2-thione group (P-TT) was prepared by polymerization of HPMA and Ma-Ah-NHNH-Boc using AIBC-TT as an initiator and functionalized CTA (CTA-TT) at a molar ratio of initiator:CTA:monomers of 1:2:400 in a mixture of the solvents tert-butanol:DMSO (80:20 (v:v)) (Šubr et al. 2013). The molar ratio of HPMA to MA-Ah-NHNH-Boc in the reaction mixture was 92:8. The dithiobenzoate $\omega$-end group was removed using AIBN as described in the literature (Perrier et al. 2005). In the second step, the amino group on the main-chain end of the polymer precursor was incorporated by the reaction of excess ethylene diamine with the thiazoline-2-thiol end group at a molar ratio of 4:1. Unreacted ethylene diamine was removed by column chromatography on Sephadex LH-20 in methanol and the polymer with the amino group $\left(\mathbf{P}-\mathbf{N H}_{2}\right)$ was separated by precipitation to ethyl acetate.

Analogously to above described procedure, the polymer precursor with azido end groups $\left(\mathbf{P}-\mathbf{N}_{3}\right)$ was prepared by RAFT polymerization using AIBC- $\mathrm{N}_{3}$ as an initiator and functionalized CTA $\left(\mathrm{CTA}-\mathrm{N}_{3}\right)$ at a molar ratio of initiator:CTA:monomer of 1:2:400 (Šubr et al. 2013).

\section{Synthesis of star polymer precursors}

Star precursor 1 (SP1) was prepared by reaction of $\mathbf{P}-\mathrm{NH}_{2}$ and $\gamma$-cyclodextrin-NHS. $\gamma$-cyclodextrin-NHS (4.6 mg, $1.2 \mu \mathrm{mol})$ and $\mathbf{P}-\mathbf{N H}_{2}(170 \mathrm{mg}, 9.2 \mu \mathrm{mol})$ were dissolved in $1.7 \mathrm{ml}$ anhydrous DMA and stirred at laboratory temperature. After $3 \mathrm{~h}$, the product was precipitated to ethyl acetate, filtered and dried under vacuum.

Star precursor 2 (SP2) was prepared by click reaction of $\mathbf{P}-\mathbf{N}_{3}$ and $\gamma$-cyclodextrin-DBCO. SP2 was prepared at same molar ratio and separated by same procedures as for SP1.

In both polymer precursors the free hydrazide groups necessary for drug attachment were obtained by deprotection of Boc-hydrazides with concentrated TFA as described recently (Chytil et al. 2010).

\section{Characterization of linear and star polymer precursors}

Determination of the molecular weight and dispersity of the copolymers was performed with a size exclusion chromatography (SEC) Shimadzu system equipped with an SPD-M20A photodiode array detector (Shimadzu, Japan), differential refractometer (Optilab®rEX), and multiangle light scattering (DAWN®HELEOS II) detector (both from Wyatt Technology Co., USA), using a methanol:sodium acetate buffer (0.3 M; pH 6.5) mixture (80:20 (v:v); flow rate $\left.0.5 \mathrm{ml} \cdot \mathrm{min}^{-1}\right)$.

The content of the TT groups on the polymer precursors was determined by UV/VIS spectrophotometry in methanol using a molar absorption coefficient of $\varepsilon_{305}=10,700 \mathrm{l} \cdot \mathrm{mol}^{-1} \cdot \mathrm{cm}^{-1}$.

The content of the azide groups was determined spectrophotometrically after derivatization with DBCOFluor 545. Excess DBCO-Fluor 545 was used and the unreacted dye was removed by gel filtration on a Sephadex LH-20 column in methanol with the aim of quantitatively modifying the azide groups. The content of the azide groups was measured by UV/VIS spectrophotometry in methanol using a molar absorption coefficient of $\varepsilon_{544}=54,000 \mathrm{l} \cdot \mathrm{mol}^{-1} \cdot \mathrm{cm}^{-1}$ estimated for the fluorescent dye DBCO-Fluor 545.

The content of the hydrazide groups was determined using the modified TNBSA assay as described in the literature (Etrych et al. 2001).

\section{In vitro degradation of star precursors}

The star polymer precursors were incubated in phosphate buffers ( $0.2 \mathrm{M}$, Sorensen) of $\mathrm{pH} 5$ and 7.4 using a polymer concentration of $3 \mathrm{mg} \cdot \mathrm{ml}^{-1}$. The amount of degraded linear polymer was determined by SEC (column 
TSKgel 4000, system and procedure described above) from the relative area of peaks (RI detector) of linear polymer and high-molecular-weight polymer precursor.

\section{Results}

\section{Synthesis of cyclodextrin derivatives}

Modified $\gamma$-cyclodextrin designed for aminolytic reaction with the amino groups of $\mathbf{P}-\mathbf{N H}_{2}$ was successfully synthesized at high conversion. Modification of $\gamma$-cyclodextrin with succinic anhydride and $N$-hydroxysuccinimide yielded a product with an average of 9 NHS residues on the $\gamma$-cyclodextrin ring (Fig. 1A). MALDI-TOF analysis showed that the distribution of the succinic residues was not fully homogeneous, as

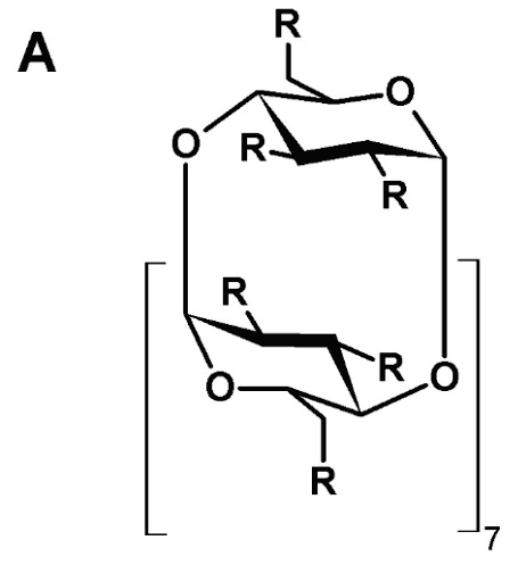<smiles>[R]OO</smiles>

Fig. 1. (A) $y$-cyclodextrin-NHS, (B) $y$-cyclodextrin-DBCO.

\section{Synthesis of linear polymers}

The semitelechelic polymers $\mathbf{P}-\mathbf{N}_{\mathbf{3}}$ and P-TT, with Boc-protected hydrazide groups along the polymer chain, were prepared by RAFT polymerization using both the CTA and the initiator containing the given functional group $\left(\mathrm{N}_{3}\right.$ or $\left.\mathrm{TT}\right)$ to ensure the functionality close to unity. Controlled RAFT polymerization carried out at $70{ }^{\circ} \mathrm{C}$ was successful for synthesis of both linear copolymers with an $M_{n}$ of approximately $20,000 \mathrm{~g} \cdot \mathrm{mol}^{-1}$ (Table 1) and low dispersity (up to 1.1). The semitelechelic polymer $\mathbf{P}-\mathbf{N H}_{2}$ was prepared by reacting modified $\gamma$-cyclodextrin with 6 to 12 residues was found in the sample.

The cyclodextrin derivate with DBCO groups was prepared by esterification reaction of DBCO-acid with primary hydroxyl groups of $\mathrm{CD}$. The reaction was monitored by HPLC and the product characterized by MALDI-TOF. Unreacted DBCO-acid was successfully removed by precipitation to ethyl acetate. In the case of $\gamma$-cyclodextrin-DBCO, an average of seven DBCO groups on one molecule of cyclodextrin was found. A higher degree of modification was reached for $\gamma$-cyclodextrin-NHS than $\gamma$-cyclodextrin-DBCO, probably due to the steric hindrance of the bulky DBCO molecule within the modification of the small $\gamma$-cyclodextrin molecule.
B
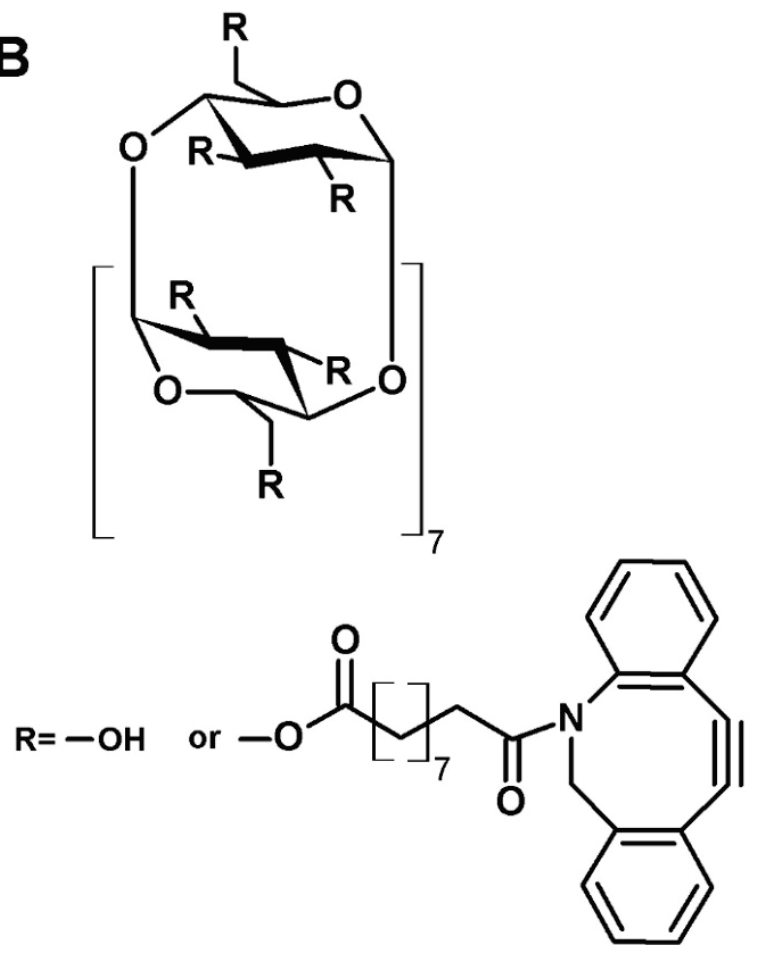

an excess of ethylene diamine with the TT groups of P-TT. The conversion of the TT groups to amino groups proceeded at high yield and the semitelechelic polymer $\mathbf{P}-\mathbf{N H}_{2}$ (Fig. 2), with high functionality was obtained $(\mathrm{F}=0.90)$. The polymer modification changed neither the molecular weight nor the dispersity of the prepared precursor, thus showing that the possible crosslinking of polymer precursors did not occur. The dithiobenzoate-end groups of both polymer precursors, P-TT and $\mathbf{P}-\mathbf{N}_{3}$, were removed quantitatively using excess $\mathrm{AIBN}(20 \mathrm{wt} \%)$ in DMSO. 
Table 1. Linear precursors.

\begin{tabular}{lccccc}
\hline Sample & $\begin{array}{c}\boldsymbol{M}_{\boldsymbol{n}} \\
\left(\mathbf{g} \cdot \mathbf{m o l}^{-\mathbf{1}} \mathbf{)}\right.\end{array}$ & $\begin{array}{c}\boldsymbol{M}_{\boldsymbol{w}} \\
\left(\mathbf{g} \cdot \mathbf{m o l}^{-\mathbf{1}}\right)\end{array}$ & $\mathbf{D}$ & $\begin{array}{c}\mathbf{F} \\
(\text { end group) }\end{array}$ & $\begin{array}{c}\text { Hydrazide } \\
\mathbf{c o n t e n t}(\mathbf{m o l} \%)\end{array}$ \\
\hline$P-T T$ & 18,900 & 20,800 & 1.10 & 0.98 & 4.2 \\
$P-N H_{2}$ & 18,600 & 21,000 & 1.13 & 0.90 & 4.2 \\
$P-N_{3}$ & 22,100 & 24,200 & 1.09 & 0.90 & 3.6 \\
\hline
\end{tabular}
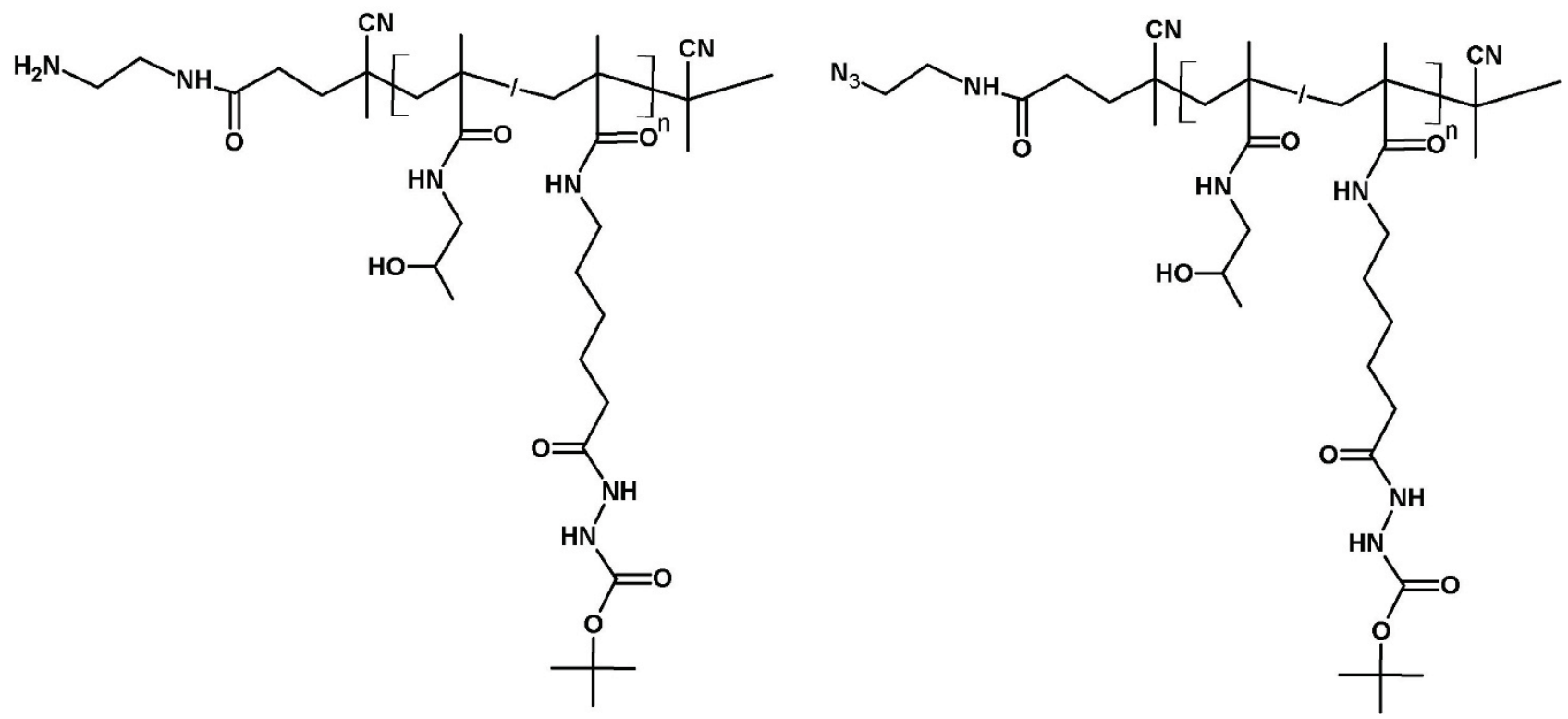

Fig. 2. Schematic structure of the linear precursors $P-N_{2}$ and $P-N_{3}$.

Synthesis of star polymer precursors

Two different polymer precursors SP1 and SP2 (characterization is in Table 2), differing in the conjugation method between the core and pHPMA, were prepared. By reacting the amino groups of $\mathbf{P}-\mathbf{N H}_{2}$ with $\gamma$-cyclodextrin-NHS, we were able to attach the polymer grafts via amide bonds to the CD core (SP1) at high yield. The molecular weight of SP1 was $121,000 \mathrm{~g} \cdot \mathrm{mol}^{-1}$, implying that six or seven polymer arms were bound to one molecule of the $\gamma$-cyclodextrin core. The conversion of the reactions was approximately $80 \%$. Similarly, SP2 was successfully synthesized by non-catalyzed click reaction. A semitelechelic polymer containing an azido end group was used for click reaction with CD-DBCO. Prepared high-molecular-weight polymer (SP2) had an $M_{n}$ of approximately 145,000 , i.e. similar to the above mentioned case, approximately six or seven polymer chains were grafted onto the $\mathrm{CD}-\mathrm{DBCO}$ core, proving the full conversion of DBCO groups in the click reaction. The advantage of the click reaction was unambiguously demonstrated, as no deactivation was found in compared to the partial hydrolytic deactivation of the NHS ester. Both synthesized star polymer precursors had low dispersity and were fully water-soluble.

Table 2. Star precursors.

\begin{tabular}{lccccc}
\hline Sample & $\begin{array}{c}\text { Used linear } \\
\text { precursor }\end{array}$ & $\begin{array}{c}\boldsymbol{M}_{\boldsymbol{n} \text { (star) }} \\
\left(\mathbf{g} \cdot \mathbf{m o l}^{-\mathbf{1}}\right)\end{array}$ & $\mathbf{Ð}_{(\text {star })}$ & $\begin{array}{c}\text { Star : Linear } \\
(\mathbf{\%})\end{array}$ & $\begin{array}{c}\text { No. of polymer } \\
\text { arms on the core }\end{array}$ \\
\hline$S P 1$ & $\mathrm{P}^{-\mathrm{NH}_{2}}$ & 121,000 & 1.3 & $85: 15$ & 6.5 \\
$S P 2$ & $\mathrm{P}^{-\mathrm{N}_{3}}$ & 145,000 & 1.3 & $77: 23$ & 6.5 \\
\hline
\end{tabular}


Degradation of star polymers

Degradation study (Fig. 3), of the star-like copolymers SP1 and SP2 was carried out at pH 5.0, which corresponds to the intracellular condition of tumor cells (secondary lysosomes) and $\mathrm{pH} 7.4$, which is the $\mathrm{pH}$ typical for physiological conditions in blood. Both star

\section{SP1}

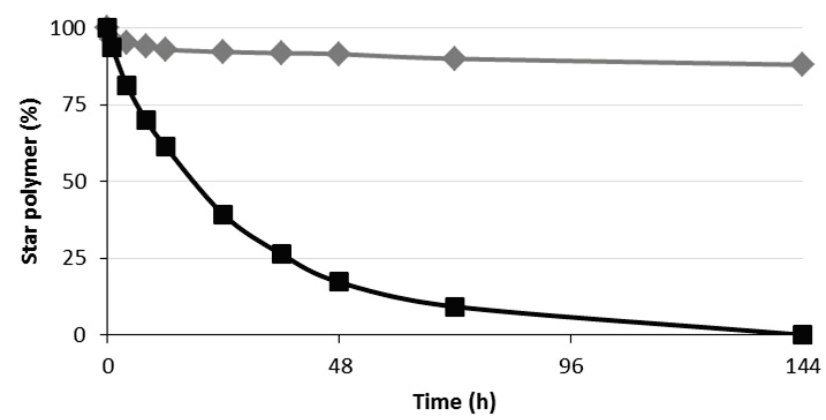

Fig. 3. Degradation of SP1 and SP2 (pH 5 - grey, $\mathrm{pH} 7.4$ - black).

\section{Discussion}

The main aim of the present paper was the synthesis and characterization of new polymer carrier systems suitable for controlled drug delivery. The design and synthesis of well-defined biodegradable structures of high-molecular-weight polymer carriers is of great interest to many research groups worldwide. We prepared novel well-defined biodegradable star polymers by grafting linear pHPMA copolymers onto a $\gamma$-cyclodextrin core. To ensure the low dispersity of the star polymers, linear polymer precursors with low dispersity and high functionality were synthesized using controlled RAFT polymerization.

\section{Synthesis of polymer precursors}

The polymer backbone of HPMA-based copolymers is not biodegradable. Therefore, only polymers with molecular weights under the limit of renal filtration $\left(M_{\mathrm{w}}\right.$ below $\left.50,000 \mathrm{~g} \cdot \mathrm{mol}^{-1}\right)$ can be used as carriers in drug delivery systems. Therefore, the controlled RAFT polymerization conditions were optimized with the intention of obtaining copolymers with a $M_{\mathrm{w}}$ below the renal threshold while maintaining the low dispersity of the precursors. Although the synthetic procedure consisted of several steps, starting with polymerization and continuing with the removal of the terminal dithiobenzoate groups and the post-polymerization modification of TT groups in the case of $\mathbf{P}-\mathbf{N H}_{2}$, almost monodispersed copolymers were polymers degraded faster in $\mathrm{pH}$ 7.4. A significant difference in the degradation rate between the conjugates was observed. While SP1 had a half-life of approximately 20 hours, SP2 had a half-life of almost forty days at pH 7.4.

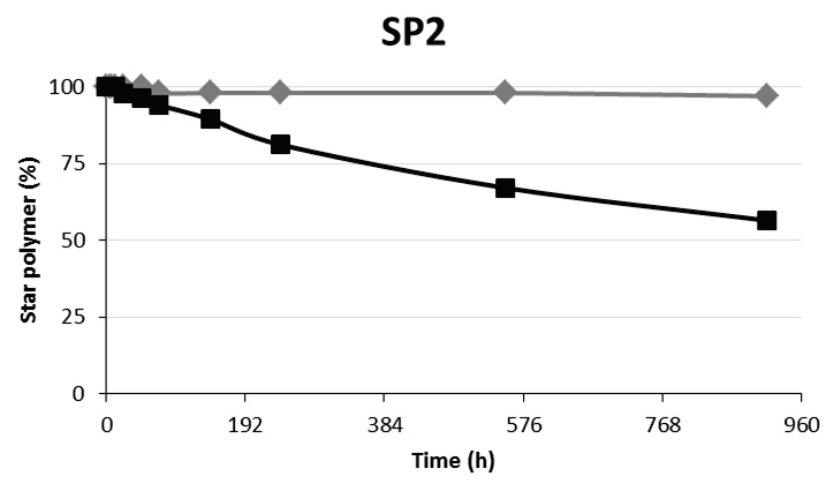

obtained This means that the majority of their polymer chains had a molecular weight of approximately $20,000 \mathrm{~g} \cdot \mathrm{mol}^{-1}$, which was fully suitable for further synthetic steps. Similarly, the functionality of both polymer precursors was kept high after the deprotection or modification, thus enabling further reaction with modified $\gamma$-cyclodextrins. Moreover, the amount of hydrazide groups on the polymer precursor after acidic deprotection was enough for the attachment of $10 \mathrm{wt} \%$ of doxorubicin, an anthracycline cytostatic drug.

\section{Modification of $C D$}

Cyclodextrins are widely studied molecules and many research groups focus on the synthesis of welldefined modified CDs and the specific modification of their hydroxyl groups. In our case, we focused on the verification of the possibility of firstly preparing biodegradable high-molecular-weight star polymers with a CD core. Therefore, we used cyclodextrins as the multifunctional core for the attachment of the watersoluble polymer to obtain star polymer precursors. We successfully modified enough hydroxyl groups of CDs, which enabled the synthesis of star polymers with 6 or 7 polymer arms.

The reaction of DBCO-acid or succinanhydride with hydroxyl groups on $\gamma$-cyclodextrin led to a statistical distribution of DBCO or succinic residues on the CDs. After the reaction, we obtained a mixture of variously modified CDs with a sufficient quantity of DBCO or succinic residues. An average of seven DBCO molecules 
and twelve succinic residues per CD were introduced for the star polymer precursor reaction. The subsequent activation of the carboxyl groups on the succinic residue enabled the preparation of activated modified CDs for the aminolytic reaction.

Synthesis of star polymer precursors and their degradation

The accumulation rate of HPMA copolymer systems is molecular-weight dependent (Etrych et al. 2012). Therefore, we aimed to prepare star HPMA copolymer systems with CD-degradable cores with similar molecular weights of approximately 120 to $150 \mathrm{~kg} \cdot \mathrm{mol}^{-1}$. These systems can prolong blood circulation and after degradation following drug release, the linear polymer chain can be removed by renal filtration, thus minimizing the potential risk of long-term accumulation of polymer carriers in the body.

Star polymer SP1 was obtained by aminolytic reaction of semitelechelic $\mathbf{P}-\mathbf{N H}_{2}$ with highly modified cyclodextrin-NHS. Despite the number of functional groups on cyclodextrin, star polymers with a narrow distribution of molecular weights, thus demonstrating the presence of 7 polymer chains on one core, were successfully synthesized. Using the low-dispersed semitelechelic polymer precursor with a functionality close to unity enable the tailored synthesis of well-defined star polymer carriers at high yield. The narrow distribution demonstrated that the maximum number of connected linear polymers on the small molecules of cyclodextrin (16.9 Ä (Zhang and Ma 2013)) is 7 linear polymer chains. We believe that steric hindrance does not allow more polymer chains to be attached to the $\mathrm{CD}$ core. Similarly, modification of cyclodextrin with an average of seven DBCO groups was sufficient for the synthesis of the star polymer precursor SP2 showing almost the same physico-chemical properties. We can conclude that the non-catalyzed click reaction is a highly valuable method for star polymer construction, as the yield of the reaction reaches almost $100 \%$. Although the modified cyclodextrin used in the following reactions was not purified and thus contained a mixture of molecules with different amounts of functional groups, the prepared star polymer precursors showed a narrow distribution of molecular weights, which makes them suitable for further investigation in the drug delivery field.

Degradation of star polymer systems is important for the removal of polymers from the organism after fulfilling their role as high-molecularweight drug carriers. The use of ester bonds, universally biodegradable either by spontaneous or enzymatic hydrolysis, as linkages between the core and the polymer arms should guarantee hydrolytic degradation of the prepared systems. Generally, ester bonds are degraded faster at $\mathrm{pH} 7.4$ than 5.0. Therefore, our systems will be degraded preferably in the bloodstream or by enzymatic degradation in lysosomes. SP1 was degraded quite rapidly at $\mathrm{pH} 7.4$ and $50 \%$ of the released linear polymer was detected during $20 \mathrm{~h}$. By using a more hydrophobic DBCO molecule containing a spacer, the stability of the polymer system was greatly increased, as the stability was more than 40 times higher. From these results it can be concluded that chemical surroundings of the ester bond has a great influence on the degradation rate of the ester bond and that the rate of the release should be determined by the proper selection of the chemical structure of the spacer between the core and the polymer chains. In respect to the rate of degradation, we can conclude that both star polymers are suitable for further investigation, but in different areas of the drug delivery field. As the degradation of SP1 is rapid, it should be used for the design of a system for neoplastic treatment, where degradation in days is advantageous. On the other hand, SP2 should be a good candidate for the treatment of inflammation diseases, which generally require more prolonged treatment over a period of weeks.

\section{Conclusions}

Two water-soluble star polymer precursors based on HPMA copolymers differing in the spacer between the $\mathrm{CD}$ core and polymer chains were successfully synthesized and characterized. Prepared star polymers had similar $M_{w}$ of approximately $180,000 \mathrm{~g} \cdot \mathrm{mol}^{-1}$, and low dispersity, around 1.3 , proving their suitability in the drug delivery field. Through the use of various reaction approaches, similar precursors with significant differences in degradation rate were obtained. We believe that the more stable SP2 is a promising system which can be used as a long-term circulation depot for drug delivery and inflammation treatment or in the treatment of other diseases requiring long-term treatment. Nevertheless, rapidly degradable SP1, which has the same precursor but with a different spacer between the core and the polymer arm, can provide fast transport of low-molecular-weight 
substances to tumor tissues and the elimination from the organism within a few hours.

\section{Conflict of Interest}

There is no conflict of interest.

\section{Acknowledgements}

This work was supported by the Ministry of Education, Youth and Sports of CR within the National Sustainability Program II, Project BIOCEV-FAR LQ1604.

\section{References}

CHYTIL P, ETRYCH T, KŘÍŽ J, ŠUBR V, ULBRICH K: N-(2-Hydroxypropyl)methacrylamide-based polymer conjugates with $\mathrm{pH}$-controlled activation of doxorubicin for cell-specific or passive tumour targeting. Synthesis by RAFT polymerisation and physicochemical characterisation. Eur J Pharm Sci 41: 473-482, 2010.

CHYTIL P, ŠíROVÁ M, KOZIOLOVÁ E, ULBRICH K, ŘÍHOVÁ B, ETRYCH T: The Comparison of in vivo properties of water-soluble HPMA-based polymer conjugates with doxorubicin prepared by controlled RAFT or free radical polymerization. Physiol Res 64 (Suppl 1): S41-S49, 2015.

ETRYCH T, KOVÁŘ L, STROHALM J, CHYTIL P, ŘÍHOVÁ B, ULBRICH K: Biodegradable star HPMA polymerdrug conjugates: Biodegradability, distribution and anti-tumor efficacy. J Control Release 154: 241-248, 2011.

ETRYCH T, ŠUBR V, STROHALM J, ŠÍROVÁ M, ŘíHOVÁ B, ULBRICH K: HPMA copolymer-doxorubicin conjugates: The effects of molecular weight and architecture on biodistribution and in vivo activity. $J$ Control Release 164: 346-354, 2012.

ETRYCH T, JELÍNKOVÁ M, ŘÍHOVÁ B, ULBRICH K: New HPMA copolymers containing doxorubicin bound via $\mathrm{pH}$-sensitive linkage: Synthesis and preliminary in vitro and in vivo biological properties. $J$ Control Release 73: 89-102, 2001.

ETRYCH T, STROHALM J, CHYTIL P, ŘÍHOVÁ B, ULBRICH K: Novel star HPMA-based polymer conjugates for passive targeting to solid tumors. J Drug Target 19: 874-889, 2011.

HARADA A, HASHIDZUME A, TAKASHIMA Y: Cyclodextrin-based supramolecular polymers. Chem Soc Rev 38 : $875-882,2009$.

HUANG X, APPELHANS D, FORMANEK P, SIMON F, VOIT B: Synthesis of well-defined photo-cross-linked polymeric nanocapsules by surface-initiated raft polymerization. Macromolecules 44: 8351-8360, 2011.

KOPECEK J, KOPECKOVÁ P, MINKO T, LU ZR, PETERSON CM, KOPECKOVA P, MINKO T, LU ZR, PETERSON CM: Water soluble polymers in tumor targeted delivery. J Control Release 74: 147-158, 2001.

KOSTKA L, ETRYCH T: High-molecular-weight HPMA-based polymer drug carriers for delivery to tumor. Physiol Res 65 (Suppl 2): S179-S190, 2016.

LIDICKÝ O, ŠÍROVÁ M, ETRYCH T: HPMA copolymer-based polymer conjugates for the delivery and controlled release of retinoids. Physiol Res 65 (Suppl 2): S233-S241, 2016.

MATSUMURA Y, MAEDA H: A new concept for macromolecular therapies in cancer chemotherapy: mechanism of tumouritropic accumulation of proteins and the antitumour agent SMANCS. Cancer Res 6: 6387-6392, 1986.

NAN A, CROFT SL, YARDLEY V, GHANDEHARI H: Targetable water-soluble polymer-drug conjugates for the treatment of visceral leishmaniasis. J Control Release 94: 115-127, 2004.

PERRIER SS, TAKOLPUCKDEE P, MARS CA: Reversible addition - fragmentation chain transfer polymerization: end group modification for functionalized polymers and chain transfer agent recovery. Macromolecules 38: 2033-2036, 2005.

POLA R, JANOUŠKOVÁ O, ETRYCH T: The pH-dependent and enzymatic release of cytarabine from hydrophilic polymer conjugates. Physiol Res 65 (Suppl 2): S225-S232, 2016.

SINGER JW, BHATT R, TULINSKY J, BUHLER KR, HEASLEY E, KLEIN P, DE VRIES P: Water-soluble poly-(L-glutamic acid)-Gly-camptothecin conjugates enhance camptothecin stability and efficacy in vivo. J Control Release 74: 243-247, 2001.

ŠUBR V, KOŇÁK Č, LAGA R, ULBRICH K: Coating of DNA/Poly(l-lysine) complexes by covalent attachment of Poly[ $N$-(2-hydroxypropyl)methacrylamide]. Biomacromolecules 7: 122-130, 2006. 
ŠUBR V, KOSTKA L, STROHALM J, ETRYCH T, ULBRICH K: Synthesis of well-defined semitelechelic Poly[N-(2-hydroxypropyl)methacrylamide] polymers with functional group at the $\alpha$-end of the polymer chain by RAFT polymerization. Macromolecules 46: 2100-2108, 2013.

ULBRICH K, ETRYCH T, CHYTIL P, JELÍNKOVÁ M, ŘíHOVÁ B: Antibody-targeted polymer-doxorubicin conjugates with pH-controlled activation. J Drug Target 12: 477-489, 2004.

ULBRICH K, ŠUBR V, STROHALM J, PLOCOVÁ D, JELÍNKOVÁ M, ŘíHOVÁ B: Polymeric drugs based on conjugates of synthetic and natural macromolecules. I. Synthesis and physico-chemical characterisation. J Control Release 64: 63-79, 2000.

ULBRICH K, HOLÁ K, ŠUBR V, BAKANDRITSOS A, TUČEK J, ZBOŘIL R: Targeted drug delivery with polymers and magnetic nanoparticles: covalent and noncovalent approaches, release control, and clinical studies. Chem Rev 116: 5338-5431, 2016.

ZHANG J, MA PX: Cyclodextrin-based supramolecular systems for drug delivery: recent progress and future perspective. Adv Drug Deliv Rev 65: 1215-1233, 2013. 